\title{
CONTRIBUTIONS TO THE TREATMENT OF UTERINE DISEASE.
}

By FDWARD L. FALLOON, Esq.

Considering that the views put on record, and the practice advocated during the last two years, in the able work of Dr. Henry Bennet, are so opposed to previous and still prevailing opinions on uterine disease as expounded by our ablest obstetricians, it is surprising that detailed reports in confirmation of his statements have not appeared in greater abundance. The profession, in fact, has been nearly silent, so far as the publication of clinical experience is concerned; for the energetic denunciations of controversial writers have not given proof of much actual practice on the part of the combatants. It is therefore with the hope of contributing to the supply of what appears to be a want, that I now offer the result of much attention to the subject during the last three years. I trust that my example may be soon followed by others, whose capabilities and opportunities of investigation are more ample.

Personally unknown to Dr. Bennet, I approach the subject with an unprejudiced mind, my sole design being to test the accuracy of his statements, as I am solicitous only for the supremacy of truth. In relating cases of "chronic inflammation and ulceration of the cervix uteri", I shall endeavour to avoid a wearisome detail of similar cases, by giving specimens as they are met with in practice, under different circumstances, and in varying conditions of life. I proceed, then, to relate six cases;-in the relation of which there must of necessity be some degree of similarity.

1. In the married state, where children have not been borne.

2. In the unimpregnated state, where children have been borne.

3. In the newly married.

4. In the pregnant.

5. In the widow.

6. In advanced life.

These will include all phases of female existence, except the virgin state, in which, however, the disease is found (and in which I have treated some cases very successfully); but, for obvious reasons, such cases do not nearly so frequently present themselves.

Case I. In April 1850, I was requested by her husband to visit Mrs. A., aged 21. She had been married two years and a half, but had had no family. She was the child of healthy parents, and looked fresh herself; I had some difficulty on this account in getting the information I required. She stated that before her marriage, she had suffered for two years at her monthly periods in increasing measure; she felt as if something was wrong in the neighbourhood of her womb; had pain in the right ovarian region, but took little notice of it, never mentioning it to her mother; she was afraid of the touch. After her marriage she enjoyed tolerable health; but the catamenia ceased. After a long walk, she miscarried ten months after her marriage; this was attended with considerable hæmorrhage, for which no treatment was had recourse to. Ever since, her former symptoms have been aggra- 
vated. She now suffers much at her catamenial periods, which return too frequently, and are preceded by hysterical spasms, and sense of weight in the pelvis after walking: she is also easily fatigued, every emotion of the mind producing pain in the right side, which she characteristically describes as "something moving there"; she has constipation, unrefreshing nights, awaking tired with a clammy tongue; has anorexia, pruritus, slight pain on coition, and purulent discharge per vaginam. Notwithstanding all these symptoms (not one of which I should have been told, had I not interrogated closely), she pressed upon me how well she was; but has since acknowledged that she never told me how ill she was, and how much she suffered. I had not acquired so much information about, or such expertness in the management of these cases then, as I since have in the school of experience; still, I felt I could not conduct this case satisfactorily without an examination, to which she intelligently consented. The uterus was of healthy size, moveable, sensitive, and slightly retroverted, the cervix felt flattened and hypertrophied, the os open, with a velvety margin; the speculum detected an extensive ulceration of the size of half a crown, with raised hardened edges, and granular bleeding surface. I need not enter into the details of treatment; suffice it to say, it consisted in the application to the os uteri of six leeches once repeated, cauterisation with the nitrate of silver, alternated with the acid nitrate of mercury, at intervals of not less than five or six days, with the use of aluminous injections and the cold hip-bath for a period of ten months, with progressive local and general improvement.

She was not seen for a month or more, when she returned, stating she felt her right ovarian pain slightly again, and some of her old feelings; that she had noticed gushes of pure water from the vagina lately, at intervals of two or three days, so much so as to saturate her dress, without any pain. On examination, the cicatrix of the former ulcer was very evident, looking moist and vesicular, but without any other evidence of the disease which these symptoms indicate : the os uteri was still too open. I cauterised the whole surface with nitrate of silver, which gave more pain than at any former time; and passed one of Dr. Bennet's smaller sized cylinders of potassa c. calce, into the cavity of the os; the pain from which was soothed by a little inhalation of chloroform. After three months, there was no more gushing of water, her general health was good, the menses regular and much less painful, and the os was closed so as hardly to admit a No. 5 bougie; she could walk any ordinary distance without fatigue or inconvenience; in fact, she felt and looked well.

June 1, 1851. I saw this lady to-day, and the report was most favourable; her only complaints were, being rendered uncomfortable by connexion, and feeling swollen. There was slight vaginitis, which was relieved by leeches.

September 19, 1851. All her ailments have ceased to exist. The only symptom left was the right ovarian pain on any excitement, fatigue, or fright; for this I tried the opiate suppository, so highly spoken of by that distinguished obstetrician, Dr. F. Churchill, in an article in the Dublin Quarterly.Journal of Medical Science for August 1851. I have seen her since, and she told me she derived decided benefit from it.

Remarks. The chief points of interest in this case consist in the disproportion between the amount of complaint made by the 
patient herself, and the extent of disease found on investigation. Had I contented myself by treating the disease as she represented it, without special interrogatories arising out of a study of this particular form of disease, the result proves that I should never have treated it successfully. That her ailments did arise from the uterine disease, is proved by the fact, that she recovered without any medicine, except an occasional aperient; it shows, moreover, to what an extent the lucal disease may progress, without any consciousness on the part of the patient.

CASE Ir. My second case occurred in a married woman, who had borne children, but was not pregnant during treatment. Mrs. B., aged 46, mother of nine children, had had two abortions; she never felt well since her last confinement, twelve years ago. I attended her in December 1850, for bronchitis. She recovered and went to the country. On returning to town, she became debilitated; all the secretions were out of order; the urine scanty, highly charged with lithates; the bowels irregular, sometimes too free, at other times constipated; she had emaciation, white tongue, restless nights, weariness: in the mornings, anorexia, nausea, and extreme retching. I endeavoured to meet these symptoms by appropriate treatment, with partial success; but her health did not improve in proportion. I was requested to see her in the month of January following, for a severe pain under her left breast, not increased by a deep inhalation or pressure, which resisted all external irritants, and was accompanied by occasional chills and evening flushings. $\mathrm{Up}_{\mathrm{p}}$ to this time, the treatment of this case was most unsatisfactory to my mind; I scarcely knew what to make of her. When I happened to inquire if she never had a pain lower down, she said, "Yes, for a long time; a curious pain, like the ticking of a watch, as if something moved there", in the left ovarian region. I then found she had a purulent discharge: the catamenia were still regular, but excessive and painful. On these grounds alone I examined her, and found an hypertrophied cervix, flattened and indurated, an ulceration of considerable extent around the os (which was open enough to admit the first phalanx), penetrating high up the cavity, and covered with pus.

Here, then, was the secret of all her hitherto anomalous symptoms. I confess I was nigh leaving her, in perfect ignorance as to what was the matter; and this one "curious pain", as she called it, led me to suspect the cervical ulceration. It was most satisfactory to my mind. Cauterisation with nitrate of silver, weekly repeated, and aluminous injections, were persisted in for the space of two months, with slow improvement, as the ulceration was unusually extensive, and of long standing; the hypertrophy was so enormous, as hardly to enter the largest speculum of Coxeter's, when dilated to the full. She was beginning to lose heart, and I was disappointed with the tediousness of her case, when I happened to read Dr. Bennet's paper on the superior advantages of the potassa cum calce in these chronic cases; and I directed Mr. Lowe, of Islington Square, to procure me some from Squire, of Oxford-street, London. I used it on two occasions, at intervals of three weeks; its application gave little pain, but nothing could be more marked than her improvement: the uterus, which was very low down, had regained its place; the indurations melted down, and the os contracted to its normal size and natural hue, without any ulceration; all her general symptoms vanished; and she is able to return to 
her duties in her shop, and go through a great amount of exertion, without fatigue, or feeling it a labour as formerly; so that little better than three months have elapsed since the first cauterization up to perfect cure of all her unaccountable ailments, without, I may say, any medical treatment, except a few bismuth powders. I saw her on the 12th May 1851 ; her health, strength, and happy looks, were perfectly restored; the catamenia returned regularly without pain; in fact, she was without back-ache, head-ache, or heart-ache.

It is quite clear to any unbiassed intelligent mind, that no amount of medicine singly, however skilfully prescribed, could have restored this woman to health, not to say one word about what the consequence might have been on the cessation of her catamenia, if no specific treatment had been adopted; viz., in all human probability an attack of cancer.

Case III. I was requested in June 1851 to see Mrs. C., aged 22. She had been married four months. The catamenia first appeared at 13, without pain, but two years ago they became very painful, requiring her to lie in bed all the first day. She had been in bad health ever since her marriage on the 25th of March, and had passed over three months without her menses appearing; but there was no other evidence of pregnancy than the morning sickness. There was no areola, nor alteration of figure. The uterus was of ordinary size. She had, however, lost flesh, rested badly, was anæmic, dispirited, and nervous to a high degree, disliked society, did not enjoy anything; the stomach rejected all or a great portion of every meal. She stated that she suffered from "whites" and occasional back-ache. Finding that she must leave on the last day of July with her husband, who was bound for the Cape, I determined to lose no time, and told her what I suspected, and that without being satisfied on this point by an examination I could give no opinion, nor would I undertake the treatment of her case. She was a sensible young woman, and yielded a ready assent. A digital examina. tion gave little pain, and conveyed the impression of a soft velvety circle, distinct from the surrounding surface; it is to be felt, not described. The os was abnormally open : the speculum brought to view a far greater amount of disease than I was prepared for, or the symptoms warranted me to expect-a true ulcer, such as would satisfy the most fastidious pathologist, of the size of half a crown; the cervix was not hypertrophied. The treatment was the ordinary cauterisation with the nitrate of silver every five days, alum injections, an occasional enema, air and carriage exercise, and no medicine. The effect was magical; after the very first application of the caustic, I had a note from her mother the next morning, stating her alarm at seeing the usual coloured discharges during the night (a slight oozing from the ulcerated surface that new patients ought to be told to expect, as a result of the cauterising), but adding, " in all other respects there is a marked improvement. She has asked for her breakfast, taken it with a relish, and kept it-what she has not done for weeks, and is quite cheery." The local and general improvement kept pace with this report; and suffice it to say, she left for the Cape, "Sana mens in corpore sano", having gained flesh and improved in health, strength, and appearance. ${ }^{1}$ Now, according to

1 October. I have been informed that the vessel was "spoken" since, and her husband writes to say, that his wife was very well, and bore the voyage admirably. 
my judgment, here is a model case, extracted verbatim from my note book; and I will thank those who have been endeavouring to pour contempt upon the modern treatment of uterine disease, to account for the rapid improrement in this young lady's case, in any other way than by admitting that the local disease was the cause of the whole of the general disturbance of her health-by the fact, that they all gave way, pari passu, with the healing of the ulceration. Dr. J. Bird in his article on "Rheumatism in the Tropics", (London Journal of Medicine, March 1851, p. 227), very adroitly tries to cast discredit on this mode of treatment, by speaking of rheumatismal dyscrasia oc. curring in all cases where the circulating fluid becomes deteriorated by the absorption of foreign poisonous matter, "as in uterine affections, that give rise to those diseased conditions now fashionably treated as local diseases, by caustic and other like applications," etc. In the above case, there was every evidence of dyscrasia; and yet that state of body gave way to the cure of the local disease, without any medical treatment whatsoever, not even a globule; although, had I been dishonest enough to use this latter fraudulent panacea, no doubt to it would have been attributed all the benefit derived.

Case IV. Mrs. D., ætat. 24, a widow, consulted me in November 1850. She stated that she had a difficult labour six years ago, and had acted imprudently in going about too soon. Three years ago, she had much watching and anxiety about her husband, who died of phthisis two years ago, her health having declined ever since. She had been under treatment for many supposed diseases, by divers medical men, each differing from the other as to the origo mali; and she had taken much medicine, without any permanent benefit. She complained of excessive sickness at night, and after meals; general prostration of strength; languor and lassitude on the slightest exertion; irritability of temper, indigestion, obstinate constipation, furred and indented tongue; passed restless nights; a dull pain in the left ovarian region; purulent discharge per vaginam; bearing down; suffered pain at her menstrual periods, which were pretty regular. She seemed to have no suspicion what her disease was. On digital examination, the vagina felt hot; the cervix uteri very low; the anterior lip, elongated, hypertrophied, and tender; the os open and flabby. On separating the lips of the os uteri with the speculum, extensive ulceration was brought to view; the cavity and surrounding follicles were much inflamed. I ordered six leeches to the os, which were repeated in five days, with great benefit, though the hæmorrhage was rather prostrating last time. Cauterisation, with the nitrate, was carried on for two months, with marked improvement of the general health ; her sickness ceased; her spirits returned; all the secretions were healthily performed; indeed, her general amendment was greater than the local, as the ulcerated cavity seemed to become accustomed to the stimulus of the nitrate of silver; and it is such cases that the potassa cum calce comes to our aid with magical effect. On examining her a fortnight after its use, the elongation was removed, and the os closed to its normal size. She regained her healthy look, was able to undertake the duties of her house, and walk long distances, without pain, bearing down, or inconvenience; being in all respects a contrast to what she had been six months before. VOL. IV. 
Twelve months have now elapsed since her treatment commenced, and the above report stands good.

Here, then, is a case, where medical treatment had been skilfully applied, and signally failed; so that one is forced to feel that nothing short of the local treatment would have succeeded in effecting a perfect cure in less than four months.

Case v. In April last, I was consulted by Mrs. E., aged 66, a widow, for what she termed " a dreadful attack of piles." I gathered the following history. The catamenia appeared at fifteen, without pain; she married at twenty-one, and had four children; had excellent health; she lived in luxury up to fifteen years ago, when she had an attack of metritis, treated by rest, leeching, etc.; the menses ceased at thirty-five. Her husband died fourteen years ago, when domestic troubles pressed her sore, and her health began to decline; and, from her report, the uterine symptoms have made rapid progress, without her being aware that her womb was the seat of disease. She looked very haggard and bent down; and, on examining for the enormous piles I had been led to expect, a bleeding, ulcerated, honeycombed, shapeless mass presented itself, as large as a good sized pear, which, on ciose inspection and sponging, turned out to be the prolapsed uterus, inflamed, enlarged, and ulcerated in its whole extent. The anterior lip was so elongated as to obscure the os, until it was lifted out of the way; the first phalanx was admitted with ease into the cavity; and the cervix was greatly hypertrophied. I cauterised the whole surface with the nitrate, ordered her to lie down, live generously, use astringent injections, and enemata when necessary. This treatment was carried on for three months, with wonderful improvement; the uterus gradually lessening in size, and assuming a healthy appearance. But the improvement has been most striking during the fourth month, owing to one application of the potassa c. calce; it will not now prolapse, although no mechanical supports (I abhor them) have been used.

Six months have now elapsed since I commenced to treat this lady, and the ulceration is now quite healed, the hypertrophy is gone, the cervix has assumed a perfectly healthy look, she is twenty years younger in appearance, and can walk two miles, without prolapsus, fatigue, or pain. I may just mention, that this lady's daughter, now aged 35, has prolapsus uteri to a great extent, and that on examining her a few days ago, I found the uterus hanging out fully an inch, and a polypus projecting from its cervix.

Case vi. It only remains for me now to give a case of this disease occurring during pregnancy. I have had three interesting cases lately under these circumstances, and will briefly notice one of them. Mrs. F., aged 32, the mother of five children, (the youngest four years old), sent for me about two years ago, to attend her in a bad miscarriage, which came on without any sufficient cause. She removed to Southport, where I had occasion to go about ten months afterwards, and colled upon her, when she informed me she had had another abortion, equally unaccountable, adding at the same time, "that she was pregnant then three months, and felt as if she should miscarry while she was talking to me"; and stated that she never was without that feel,-bearing down, and inability of walking. She was hysterical to a high degree, and her general health had greatly declined, from restless nights, indi- 
gestion, etc. Her history aroused my suspicions, I told her what I suspected; and a meeting was arranged accordingly. I found the uterus very low down, os open, cervix enlarged, but not hardened. On introducing the speculum, a quantity of purulent matter oozed from the os uteri, on brushing it away, a granulating ulcer was exposed, which bled easily; the lips of the os had the usual congested appearance which they have in pregnancy. I cauterised the ulceration externally, and for half an inch up the cavity, only nine times, (as her residence was fifteen miles off, and the progress was astonishing; so that, at five months' gestation, she felt as if a load was removcd from her loins, she could walk with comfort, without bearing down, eat and slept well, and was safely confined last month.

I could give a number of such cases, showing that abortion is the almost inevitable result of this disease, if it be left undetected and untreated. Should the powers of life be so strong as to resist this disposition, or should the disease not have continued long enough to produce that depression of the organic nervous system, wasting, and general ill health, then it almost always produces premature labour; or, if the person be originally strong, and goes on to the full time, an emaciated fœtas is born, and most generally there is flooding. I have watched these cases closely, and the result was one or other of these occurrences.

I look, therefore, upon pregnancy supervening on this disease as a great misfortune, for two reasons : first, because the utcrus cannot carry on two processes-feed a foetus, and an ulcer or inflammation-without damage ; and, secondly, because we cannot be so bold in our remedial measures, nor consider it safe to use any stronger application than the nitrate of silver, which, I am persuaded, is too weak to overcome the diseased action in old standing cases. I have been more bold in the use of lunar caustic in these last cases than authorities warrant, yet I have never known any bad consequences; on the contrary, I believe it will most certainly prevent impending abortion, if the case is seen early enough. However, this disease is comparatively rare in pregnancy, as its tendency is most generally to prevent conception; and its long continuance, without detection and treatment, will most commonly produce sterility. I had a remarkable instance of its power in this respect lately. A female, who had been married upwards of four years, without conception, called upon me, during the summer. She stated, that her health had been very bad ever since her marriage; she had been under many medical men and quacks (homœopathists), without deriving any benefit. She looked haggard, livid, and anæmic; her mind was much deranged, she fancying that her husband was going to stab her in the night: she also complained of awful dreams, hyste-rical attacks, dragging about her loins, and painful (though regular) menstruation.

On examination, I found a prolapsed nterus; an hypertrophied cervix hanging externally, with an ulcer around the open os; lencorrhœa :-here was clearly the cause of all the mischief. I used the potassa c. calce at once, which gave great pain, and seemed to aggravate all her symptoms; the ulceration was dressed weekly with the nitrate of silver, and in six weeks the change was most striking; the prolapsus became less, her horrors ceased, and her general health 
improved. In consequence of the prolapsus having continued so long, I could not expect that to be perfectly cured; so I ordered her to wear (as necessary to her comfort, though ever objectionable) a new gutta percha support made by Coxeter, the best and lightest thing of the kind I know of. In two months she returned, expressing her alarm that her courses had ceased, and begging me to give her some medicine to produce their flow; with this request of course I did not comply, giving my reason, that there might be a natural cause for their cessation; at which she incredulously smiled; however, she was not a little surprised to find pains coming on her four months afterwards, which ended in a miscarriage, to her great disappointment. I recollect examining one lady, who had been married four years without family, where I found only erosion around the os, which was cured by a few touches of the caustic, and she became pregnant in two months afterwards; and $I$ have since attended her in confinement at the full time.

I must conclude by expressing my thanks to Dr. H. Bennet for the valuable instruction I have derived from the study of his writings. I commenced their investigation with an unprejudiced mind, having no theory to support, nor interest to serve, save that of truth; and my daily increasing experience in these complaints convinces me how common they are, and how appropriate is his method of cure.

I fear that the tendency of the recent papers of Dr. W. F. Mackenzie are unfavourable to the due extension and adoption of Dr. Bennet's principles. Dr. Mackenzie is an able writer; but I trust he will pardon my freedom in objecting to the manner in which some of his cases are reported, and to the inferences drawn from them. In the May Number of the Lornon Jou Rnal of Medicine, he reports some cases of what he calls irritable uterus; but when I come to study these cases, I find in almost every instance, all the symptoms of chronic inflammation and ulceration of the os uteri. Take any of the ten cases:-Case VI, for instance: " $\mathrm{Ch}$. W., suffering from great pain and bearing down, back-ache, both increased by walking and standing; leucorrhœa, painful, and frequent menstruation, prolapsus, tenderness on examination; a premature confinement eighteen months before ; tongue furred, appetite bad; constipation; disorder of stomach and digestive organs, anæmia :" and then it is added, " uterus not otherwise diseased." We are not told what measures were adopted to ascertain this important fact.

Then, again, in Case viI, after detailing as well marked a case of chronic uterine inflammation as it is possible, I am told that chronic uterine neuralgia, with these symptoms, is dependent on derangement of the general health, anæmia, etc. Now I appeal to any unprejudiced man - is this so? is it borne out by Dr. Mackenzie's own cases or those above cited by me? is it not precisely vice versa? Once more, and I have done. "Case Ix. S. W., ætat. 33, suffering for many years from constant pain in the uterine region, great pain in back and loins; profuse leucorrhcea; cervix extremely tender, no prolapsus, nor presenting any unnatural condition, except a little puckering and irregularity about the os; menstruates with great pain, suffered from hæmorrhage after each of her children, tongue for years furred, dyspepsia, constipation, anæmia, hysterical," etc. I am not 
surprised to learn at the end of the narration, that the patient received no benefit from the treatment adopted. Even had the result been otherwise, it would in no wise alter the facts; because I grant, that all my cases where anæmia, etc., existed, might have been benefited by iron and counter-irritants; but could they ever have been cured by them ? Before I knew as much as I now do about the nature of these cases, I have whitewashed many by chalybeates, rest, and banishing mothers from their homes; but let them only return to the old regime, and they invariably lapse back to that condition whence they started.

I am free to confess that Dr. Bennet's method of practice may be abused, and discredit cast upon the legitimate use of the speculum by its indiscriminate employment. But because some are found base enough to abuse medical confidence, is it therefore to be abandoned, and a good system decried?

4, Shaw Street, Liverpool, Nov. 21, 1851.

\section{MORBID VASCULARITY OF THE LINING MEMBRANE OF THE FEMALE URETHRA.}

By GEORGE T. GREAM, M.D., late one of the Medical Officers to Queen Charlotte's Lying-in Hospital.

UNDER the name of "Vascular Tumour of the Orifice of the Meatus Urinarius", this affection was first described by Sir Charles Clarke, in his valuable work on the Diseases of Women; a work giving evidence of the highly practical knowledge of that author, and which, although published more than thirty-five years ago, may still be considered as one of the best guides to the diagnosis of this class of maladies.

He writes : "There is in most women a degree of projection round the orifice of the meatus urinarius, and from this part sometimes the tumour arises, to which the above name of the vascular tumour of the meatus urinarius has been applied." I have ventured to refer to this affection under another name, because my own experience, confirmed by that of others, tends to show that it does not always appear as a tumour, but that it may be present under other forms, accompanied by the same general as well as local symptoms.

Dr. Ashwell has correctly described the disease, but he speaks of it more especially as a tumour, and states that it is rarely seen after the cessation of the menses. I am led to think that he is mistaken in this respect, for I have witnessed the disease as often in elderly women as in the young.

Dr. Meigs, of Philadelphia; has alluded to the complaint in his volume on Females and their Diseases; but he merely refers to it as a portion of the lining membrane of the urethra, "hypertrophied and inflamed, which may be readily cut off." His observations, however, are contained in a very few lines, in which the importance of the disease is altogether overlooked.

I am not aware that any other authors have noticed the affection at all; but certainly none have regarded it with that consideration which 